\title{
NOTCH2 expression is decreased in epithelial ovarian cancer and is related to the tumor histological subtype
}

\author{
Vijaya Galic ${ }^{1 *}$, Carrie J. Shawber ${ }^{1}$, Claire Reeves ${ }^{1}$, Monjri Shah² ${ }^{2}$, Aino Murtomaki ${ }^{1}$, Jason Wright ${ }^{1}$, Thomas Herzog ${ }^{1}$, Guo Xia Tong ${ }^{3}$ and \\ Jan Kitajewski ${ }^{1}$ \\ *Correspondence: vlg2110@columbia.edu \\ 'Department of Obstetrics and Gynecology, Columbia University Medical Center, New York, New York, United States of America. \\ 2Department of Obstetrics and Gynecology, University of Alabama, Birmingham Alabama, United States of America. \\ ${ }^{3}$ Department of Pathology, Columbia University Medical Center, New York, New York, United States of America.
}

\begin{abstract}
Background: Notch family members function as both oncogenes and tumor suppressors. NOTCH2 is down-regulated in colon cancer, and reduced expression is associated with a less differentiated, more aggressive phenotype, and reduced overall survival. $\mathrm{NOTCH} 2$ has also been shown to have pro-apoptotic and growth suppressive effects in thyroid carcinoma, and carcinoid tumors. The expression pattern of $\mathrm{NOTCH} 2$ in ovarian cancer is unknown.

Methods: An immunohistochemical analysis using a polyclonal antibody to the NOTCH2 intracellular domain was performed on a total of 119 ovarian carcinomas, and 7 serous borderline tumors, arranged onto tissue arrays. Normal ovarian and fallopian tube epithelium were used as controls. Specimens were scored as low or high NOTCH2 expression. The score distributions for the subtypes were analyzed with the chi square test.

Results: Fifty two of 61 (85.2\%) papillary serous, eight of 13 (61.5\%) clear cell, and 23 of 30 (76.7\%) endometrioid, demonstrated negative or lower NOTCH2 expression than normal fallopian tubal epithelium or ovarian surface epithelium. In contrast, 10 of 15 (66.7\%) mucinous carcinomas had a high level of NOTCH2 expression and consistently demonstrated intense polarized staining $(\mathrm{P}<.001)$. The apical expression of $\mathrm{NOTCH} 2$ protein present in the normal fallopian tube epithelium and many borderline tumors was absent in the high grade carcinomas, most notably in papillary serous.

Conclusion: Decreased NOTCH2 expression is associated with the poorly differentiated serous epithelial ovarian carcinoma histology. Further studies are needed to assess the functional role of NOTCH2 in ovarian cancer and its effect on prognosis.

Keywords: $\mathrm{NOTCH} 2$, ovarian cancer, tumor suppressor, immunohistochemistry
\end{abstract}

\section{Introduction}

Epithelial ovarian cancer is the most lethal gynecologic malignancy. In 2012, there were an estimated 22,280 women diagnosed with ovarian cancer with 15,500 deaths [1]. The five-year overall survival is approximately $45 \%$. Ovarian cancer collectively encompasses multiple histological types. Of these, the papillary serous histology accounts for about $60 \%$ [2]. Less common are mucinous, clear cell, and endometrioid tumors [2]. Each histological type is distinct with respect to its pathogenesis and clinical behavior, including response to chemotherapy [3]. Arguably the most important prognostic factor in ovarian cancer is stage. It is plausible that ovarian cancer, like colon or cervical cancer arises from a precursor lesion. Mucinous carcinomas and low grade serous carcinomas have been shown to coexist with borderline tumors of the corresponding histology $[4,5]$. Recently, clear cell carcinomas have been shown to arise from areas of atypical endometriosis with loss of expression of ARID1A [6]. A clear precursor lesion has not been identified for papillary serous carcinomas, which tend to present at an advanced stage. A subset of presumed serous carcinomas of the ovary or fallopian tube, however, may actually arise from intraepithelial carcinomas of the distal fallopian tube [7]. Lack of identification of a papillary serous precursor has precluded the development of effective screening tests and hampered the elucidation of early carcinogenic events in epithelial ovarian carcinoma.

Several regulators of cell fate, most notably P53 [8], BRCA1/2 [9], PTEN, and members of the PIK3 pathway [10] have been investigated in the context of ovarian cancer. Recently identified regulators of cell fate include members of the NOTCH signaling pathway. This signaling pathway is an evolutionarily conserved intercellular communication mechanism, which is mediated by the interaction of receptors and the cognate ligands on the cell membrane of neighboring cells. There are four NOTCH receptors (NOTCH 1-4) and five canonical ligands (Delta-like 1, 3 , and 4 and Jagged-1 and -2) identified in mammals. NOTCH signaling is involved in many cellular processes including cell differentiation, proliferation, survival, and apoptosis. NOTCH signaling contributes to the specification of cell lineages, tissue patterning and morphogenesis, stem cell maintenance, and 

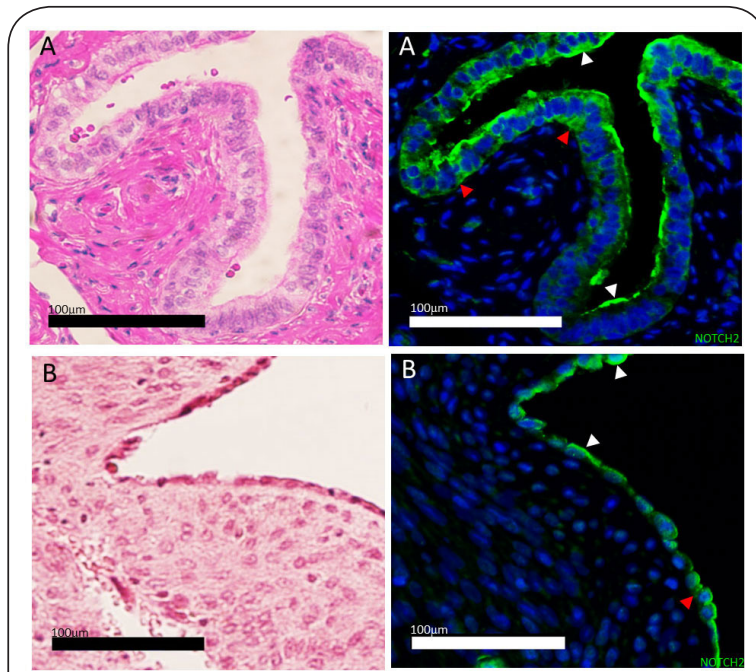

Figure 1. NOTCH2 expression in the normal epithelium. A. Upper panel H\&E staining of normal fallopian tube epithelium. Lower panel NOTCH2 staining (green) present at the apical and basal areas of the cell membrane. Nuclei are blue. B. Upper panel $\mathrm{H} \& \mathrm{E}$ staining of normal ovarian surface epithelium. Lower panel $\mathrm{NOTCH} 2$ staining (green) present at the apical and basal areas of the cell membrane. Nuclei are blue. $20 \mathrm{X}$ magnification.

tissue homeostasis during embryonic development or in adult life [11]. Abnormal NOTCH signaling is associated with various human cancers. Though classically studied in the context of tumor angiogenesis [12], NOTCH family members have also been implicated in tumor cell growth and proliferation as well as in the epithelial to mesenchymal transition $[13,14]$. NOTCH family members function in a cell type-specific and cell context-dependent manner and may function as both oncogenes as well as tumor suppressors. NOTCH1, 2 and 3, have been implicated in tumor growth regulation with the type of effect being cancer specific. NOTCH1 overexpression has been shown to promote tumor cell proliferation and invasion in breast cancer [15] and proliferation in ovarian cancer cell lines $[16,17]$. In colon cancer, NOTCH1 expression has been shown to be an adverse prognostic indicator [18]. NOTCH3 likewise has also been identified as an oncogene in serous ovarian cancer, which frequently overexpresses NOTCH3 as a result of gene amplification [19-21]. NOTCH3 overexpression in serous ovarian carcinomas has been correlated with carboplatin resistance [22]. In contrast to NOTCH1 and NOTCH3, NOTCH2 has been shown to play a tumor suppressive role in many cancers including colon, medullary thyroid [23], carcinoid [24], and colon cancer $[\mathbf{1 8 , 2 5}]$ and may correlate with increased differentiation in both colon [25] and breast cancer [26]. The role of $\mathrm{NOTCH} 2$ has not been studied in the setting of ovarian cancer. We report here our findings of $\mathrm{NOTCH} 2$ expression in normal ovary, fallopian tube, serous borderline tumors of the ovary and ovarian carcinomas.

\section{Materials and methods}

Archival pathology specimens were utilized in this study. Tissues were collected from surgical specimens following primary cytoreductive surgery for fallopian tube, primary peritoneal or ovarian cancer, or following surgery for benign gynecologic indications. Specimens were formalin fixed and paraffin embedded at the time of surgery. Tissue microarrays (TMA) containing 61 papillary serous carcinomas (PS), 13 clear cell carcinomas (CC) 30 endometrioid carcinomas (EC), and 15 mucinous carcinomas (MC) (119 cases evaluated) were assembled by three cores $(0.6 \mathrm{~mm})$ of tumor from a representative tissue block of each case. All H\&E slides were reviewed and the pathologic diagnoses were confirmed. In addition, routine tissue sections of nine serous borderline tumors were also included. The uninvolved ovarian surface epithelium and fallopian tubal epithelium served as normal tissue controls.

Immunohistochemistry of $\mathrm{NOTCH} 2$ with a rabbit polyclonal antibody to NOTCH2 (Abcam ab8926 1:100 dilution, Abcam, Cambridge, MA) was performed on the 4 micron sections from either TMA or regular tissue blocks as suggested by the manufacturer. This antibody had been previously validated by the manufacturer. Additionally, validation of the antibody was performed within our laboratory. The staining pattern was identical to that of a NOTCH2 antibody from a different manufacturer, was similar to what has previously been described by Zhang et al. in the mouse ovary, and produced a staining pattern distinct from the staining patterns of NOTCH1 and NOTCH3 (Supplement Figure S1). Immunohistochemistry of NOTCH2 with a rabbit polyclonal antibody (1:100 dilution, Abcam, Cambridge, MA) was performed on the 4 micron sections from either TMA or regular tissue blocks as suggested by the manufacturer. In brief, the sections were deparaffinized, rehydrated in decreasing concentrations of ethanol, and subjected to antigen retrieval in Target Retrieval Buffer (Dako, Carpinteria, CA) for 30 minutes. The sections were blocked in $3 \% \mathrm{BSA}$ and incubated with the NOTCH2 antibody for 10 hours at $4^{\circ} \mathrm{C}$. After washing with PBS, the sections were incubated with a fluorescent conjugated secondary antibody, Alexa Fluor 488 (Invitrogen), at a dilution of 1:10,000 for $30 \mathrm{~min}$ at $25^{\circ} \mathrm{C}$. The slides were coverslipped with Vectashield mounting medium containing DAPI for visualization of the nuclei (Vector laboratories, Burlingame, CA). The staining was examined and photographed using a Nikon fluorescent microscopy system with a digital camera. The staining was scored with a two tier system (high or low) independently by three observers based on the intensity and extensiveness of staining. Consensus was reached by re-evaluation at conference on cases with initial disagreement.

The data of staining intensities were analyzed using the chi square test included in the Microsoft excel statistical package. 

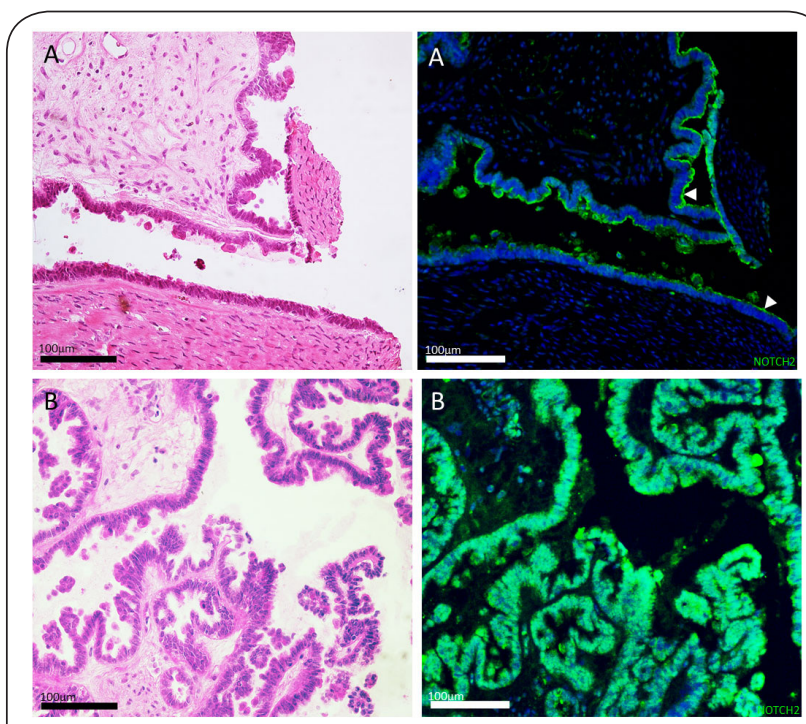

Figure 2. NOTCH2 staining in serous borderline tumors. Upper panels $\mathrm{H} \& \mathrm{E}$ staining of two serous borderline specimens. Lower panels NOTCH2 staining of corresponding specimens (green). Nuclei are blue.

A. specimen demonstrating polarized $\mathrm{NOTCH} 2$ staining. B. specimen demonstrating diffuse cytoplasmic NOTCH2 staining. Nuclei are blue. 20X magnification.

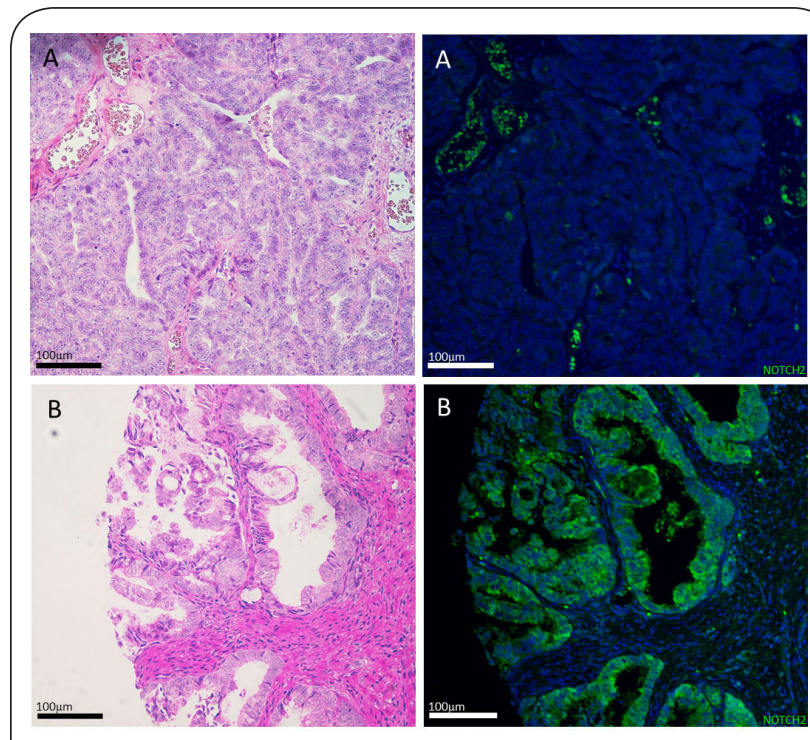

Figure 3. A. Upper panel H\&E high grade papillary serous ovarian carcinoma. Lower panel NOTCH2 staining (green) is absent. Nuclei are blue. B. Upper panel H\&E staining of mucinous ovarian carcinoma. Lower panel NOTCH2 staining (green) demonstrating high level of NOTCH2 expression with intense polarized staining. Nuclei are blue. 20X magnification.

A p value of $<.05$ was considered statistically significant.

\section{Results}

As shown in Figure $\mathbf{1} \mathbf{A}$ and $1 \mathbf{B}, \mathrm{NOTCH} 2$ staining was detected
Table 1. NOTCH2 Expression and Histology.

\begin{tabular}{lcccc}
\hline NOTCH2 & Papillary Serous & Clear Cell & Endometrioid & Mucinous \\
\hline Low & 52 & 8 & 23 & 5 \\
High & 9 & 5 & 7 & 10 \\
Totals & 61 & 13 & 30 & 15 \\
\hline
\end{tabular}

in the normal fallopian tubal epithelium and ovarian surface epithelium. The staining was strong and mainly present at the apical membranes and to a lesser extent was also seen at the basal areas of these epithelial cells. The smooth muscle cells of the fallopian tube and ovarian sex cord-stromal cells were consistently negative for NOTCH2. Four of seven of the serous borderline tumors in this study demonstrated apical distribution of NOTCH2 in the neoplastic cells as seen in the normal fallopian tube and the ovarian surface epithelium; however basal distribution of $\mathrm{NOTCH} 2$ was decreased in these cells. A representative specimen is shown in Figure $2 \mathrm{~A}$. In the remaining three cases of borderline serous adenoma, the neoplastic cells had intense diffuse cytoplasmic staining of NOTCH2 as seen in the representative specimen in Figure 2B. For the malignant epithelial tumors of the ovary, 52 of 61 (85.2\%) PS, eight of 13 (61.5\%) CC, and 23 of 30 (76.7\%) EC, demonstrated negative or lower NOTCH2 expression than normal fallopian tubal epithelium or ovarian surface epithelium tumors. Figure 3A is a representative PS with negative expression. In contrast, 10 of 15 (66.7\%) MC had a high level of NOTCH2 expression and consistently demonstrated intense polarized staining as shown in Figure 3B $(P<.001)$ (Table 1$)$.

\section{Discussion}

In this study, we investigated the expression of NOTCH2 in normal ovarian surface epithelium, fallopian tubal epithelium, and various histologic types of ovarian carcinomas utilizing immunohistochemistry. We have demonstrated that NOTCH2 is cell membrane-associated and expressed both in the apical and basal sides of the cell in the normal ovarian surface epithelium and fallopian tubal epithelium. Epithelial cells demonstrate polarized expression of several other molecules including those integral for the formation of tight junctions [27]. Further studies are needed to determine whether NOTCH2 is related to the formation and maintenance of epithelial tight junctions on ovarian epithelial cells. Of note, many of the serous borderline tumors studied contained areas in which the polarity of $\mathrm{NOTCH} 2$ expression was preserved. Even in those tumors with non-polarized membranous staining, the overall staining intensity was very high. It is not possible from immunohistochemistry observations alone to establish whether the association between high NOTCH2 expression and a non-invasive phenotype will translate into a causal relationship between loss of NOTCH2 and invasion. Further functional studies are needed to explore this.

NOTCH2 expression was present in only a small percentage of the papillary serous ovarian cancer specimens. In the context 
Galic et al. Pathology Discovery 2013,

http://www.hoajonline.com/journals/pdf/2052-7896-1-4.pdf

of the tumor suppressive role of $\mathrm{NOTCH} 2$ in colon cancer cells, it is plausible that the poorly differentiated serous carcinomas are also down-regulating $\mathrm{NOTCH2}$. Further studies are needed to clarify whether NOTCH2 down-regulation is an early causal event in high grade serous carcinoma carcinogenesis, or if the present observation is simply coincidental with a less differentiated state. While the endometrioid tumors, and clear cell specimen sets also had more tumors with low NOTCH2 expression than high NOTCH2 expression, the difference was not as pronounced as in the serous histology tumors. While the small number of specimens in these sets limits the conclusions which may be drawn, it is plausible that given the distinct carcinogenic pathways by which these tumors arise, NOTCH2 down-regulation may play a less important role in non-serous carcinomas.

Down-regulation of NOTCH2 has also been documented in colon carcinoma. Loss of expression was more commonly associated with poorly differentiated tumors [25]. Poorly differentiated tumor cells lacking NOTCH2 expression regain it after forced differentiation by butyrate exposure [25]. Interestingly, NOTCH2 expression was preserved in the majority of the ovarian mucinous tumors in the present study. This is consistent with the clinical behavior of these tumors, which unlike serous tumors, are more commonly low grade and confined to the ovary at the time of diagnosis [2].

One limitation of this study is that while the NOTCH2 antibody used in this study recognizes the intracellular domain it does not specifically identify NOTCH2 involved in active signaling. In the case of $\mathrm{NOTCH} 3$, however, the expression level of the intracellular domain alone has been shown to correlate with clinical behavior $[\mathbf{2 0}, \mathbf{2 2}]$. Another limitation of this study is that while expression differences were noted, and expression was lower in poorly differentiated tumors, no direct conclusions may be drawn regarding whether NOTCH2 is affecting tumor behavior. Additionally, it is unclear whether loss of NOTCH2 expression simply coincides with a poorly differentiated state.

The present study explores the pattern of NOTCH2 expression in epithelial ovarian cancer. As has been previously demonstrated in colon cancers, NOTCH2 expression was lost in the vast majority of poorly differentiated tumors. It is plausible therefore that $\mathrm{NOTCH} 2$ is related to tumor suppression in ovarian cancer as it is in colon cancer. Further functional experiments are required to validate the observations of the present study and to determine the role of NOTCH2 signaling in ovarian cancer cells.

\section{Additional files}

\section{Supplement Figure S1}

Competing interests

The authors declare that they have no competing interests.

Authors' contributions

Galic was responsible for study design, performed the immunohistochemistry on the tissue array, scored the array, interpreted the findings and prepared the manuscript. Shawber was responsible for the validation of the antibody for immunohistochemistry. Additionally she scored the array immunohistochemistry, provided guidance for photography and assisted with interpretation of the results. Tong constructed the tissue array, scored the immunohistochemistry and assisted with interpretation of the results and development of the manuscript. Reeves and Murtomaki assisted with photography of the array, interpretation of the results and preparation of the figures and manuscript. Herzog and Wright supplied surgical specimens and assisted with interpretation of the results and development of the manuscript. Kitajewski provided mentorship and guidance for the project overall and oversaw all aspects of study and final manuscript.

Acknowledgement

This work was supported by a grant from the NIH 5R01CA126673 to J.K. and C.S.

\section{Publication history}

Editor: Bin Guan, Johns Hopkins Medical Institutions, USA. EIC: Markus H. Frank, Harvard Medical School, USA.

Received: 29-May-2013 Revised: 31-Jul-2013

Accepted: 08-Aug-2013 Published: 16-Aug-2013

\section{References}

1. American Cancer Society. Cancer Facts \& Figures 2012. Atlanta: American Cancer Society; 2012. I Pdf

2. Schiavone MB, Herzog TJ, Lewin SN, Deutsch I, Sun X, Burke WM and Wright JD. Natural history and outcome of mucinous carcinoma of the ovary. Am J Obstet Gynecol. 2011; 205:480 e1-8. I Article I PubMed

3. Winter WE, 3rd, Maxwell GL, Tian C, Carlson JW, Ozols RF, Rose PG, Markman M, Armstrong DK, Muggia F and McGuire WP. Prognostic factors for stage III epithelial ovarian cancer: a Gynecologic Oncology Group Study. J Clin Oncol. 2007; 25:3621-7. I Article I PubMed

4. Malpica A, Deavers MT, Lu K, Bodurka DC, Atkinson EN, Gershenson DM and Silva EG. Grading ovarian serous carcinoma using a two-tier system. Am J Surg Pathol. 2004; 28:496-504. I Article I PubMed

5. Hart WR. Mucinous tumors of the ovary: a review. Int J Gynecol Pathol. 2005; 24:4-25. | Article | PubMed

6. Wiegand KC, Shah SP, Al-Agha OM, Zhao Y, Tse K, Zeng T, Senz J, McConechy MK, Anglesio MS, Kalloger SE, Yang W et al. ARID1A mutations in endometriosis-associated ovarian carcinomas. $N$ Engl J Med. 2010; 363:1532-43. | Article | PubMed Abstract | PubMed Full Text

7. Chivukula M, Niemeier LA, Edwards R, Nikiforova M, Mantha G, McManus K and Carter G. Carcinomas of Distal Fallopian Tube and Their Association with Tubal Intraepithelial Carcinoma: Do They Share a Common "Precursor" Lesion? Loss of Heterozygosity and Immunohistochemical Analysis Using PAX 2, WT-1, and P53 Markers. ISRN Obstet Gynecol. 2011; 2011:858647. | Article | PubMed Abstract | PubMed Full Text

8. Kohler MF, Kerns BJ, Humphrey PA, Marks JR, Bast RC, Jr. and Berchuck A. Mutation and overexpression of p53 in early-stage epithelial ovarian cancer. Obstet Gynecol. 1993; 81:643-50. I PubMed

9. Pal T, Permuth-Wey J, Betts JA, Krischer JP, Fiorica J, Arango H, LaPolla J, Hoffman M, Martino MA, Wakeley K, Wilbanks G, Nicosia S, Cantor A and Sutphen R. BRCA1 and BRCA2 mutations account for a large proportion of ovarian carcinoma cases. Cancer. 2005; 104:2807-16. | Article | PubMed

10. Willner J, Wurz K, Allison KH, Galic V, Garcia RL, Goff BA and Swisher EM. Alternate molecular genetic pathways in ovarian carcinomas of common histological types. Hum Pathol. 2007; 38:607-13. | Article | PubMed

11. Wang MM. Notch signaling and Notch signaling modifiers. Int J Biochem 
Galic et al. Pathology Discovery 2013,

http://www.hoajonline.com/journals/pdf/2052-7896-1-4.pdf

doi: 10.7243/2052-7896-1-4

Cell Biol. 2011; 43:1550-62. | Article | PubMed Abstract | PubMed Full $\underline{\text { Text }}$

12. Noguera-Troise I, Daly C, Papadopoulos NJ, Coetzee S, Boland P, Gale NW, Lin HC, Yancopoulos GD and Thurston G. Blockade of DII4 inhibits tumour growth by promoting non-productive angiogenesis. Nature. 2006; 444:1032-7. | Article | PubMed

13. Bao B, Wang Z, Ali S, Kong D, Li Y, Ahmad A, Banerjee S, Azmi AS, Miele $L$ and Sarkar FH. Notch-1 induces epithelial-mesenchymal transition consistent with cancer stem cell phenotype in pancreatic cancer cells. Cancer Lett. 2011; 307:26-36. | Article | PubMed Abstract | PubMed Full $\underline{\text { Text }}$

14. Yang $\mathrm{Y}$, Ahn $\mathrm{YH}$, Gibbons $\mathrm{DL}$, Zang $\mathrm{Y}$, Lin $\mathrm{W}$, Thilaganathan $\mathrm{N}$, Alvarez CA, Moreira DC, Creighton CJ, Gregory PA, Goodall GJ and Kurie JM. The Notch ligand Jagged2 promotes lung adenocarcinoma metastasis through a miR-200-dependent pathway in mice. J Clin Invest. 2011; 121:1373-85. | Article | PubMed Abstract | PubMed Full Text

15. Wang J, Fu L, Gu F and Ma Y. Notch1 is involved in migration and invasion of human breast cancer cells. Oncol Rep. 2011; 26:1295-303. I Article | PubMed

16. Rose SL, Kunnimalaiyaan M, Drenzek J and Seiler N. Notch 1 signaling is active in ovarian cancer. Gynecol Oncol. 2010; 117:130-3. | Article | PubMed

17. Wang M, Wu L, Wang L and Xin X. Down-regulation of Notch1 by gamma-secretase inhibition contributes to cell growth inhibition and apoptosis in ovarian cancer cells A2780. Biochem Biophys Res Commun. 2010; 393:144-9. | Article | PubMed

18. Chu D, Zhang Z, Zhou Y, Wang W, Li Y, Zhang H, Dong G, Zhao Q and Ji G. Notch1 and Notch2 have opposite prognostic effects on patients with colorectal cancer. Ann Oncol. 2011; 22:2440-7. | Article | PubMed

19. Park JT, Li M, Nakayama K, Mao TL, Davidson B, Zhang Z, Kurman RJ, Eberhart CG, Shih le $M$ and Wang TL. Notch3 gene amplification in ovarian cancer. Cancer Res. 2006; 66:6312-8. | Article | PubMed

20. Jung SG, Kwon YD, Song JA, Back MJ, Lee SY, Lee C, Hwang YY and An HJ. Prognostic significance of Notch 3 gene expression in ovarian serous carcinoma. Cancer Sci. 2010; 101:1977-83. | Article | PubMed

21. Cancer Genome Atlas Research Network. Integrated genomic analyses of ovarian carcinoma. Nature. 2011; 474:609-15. | Article | PubMed Abstract | PubMed Full Text

22. Park JT, Chen X, Trope CG, Davidson B, Shih le M and Wang TL. Notch3 overexpression is related to the recurrence of ovarian cancer and confers resistance to carboplatin. Am J Pathol. 2010; 177:1087-94. | Article I PubMed Abstract I PubMed Full Text

23. Truong M, Cook MR, Pinchot SN, Kunnimalaiyaan M and Chen $\mathrm{H}$. Resveratrol induces Notch2-mediated apoptosis and suppression of neuroendocrine markers in medullary thyroid cancer. Ann Surg Oncol. 2011; 18:1506-11. | Article | PubMed Abstract | PubMed Full Text

24. Pinchot SN, Jaskula-Sztul R, Ning L, Peters NR, Cook MR, Kunnimalaiyaan $\mathrm{M}$ and $\mathrm{Chen} \mathrm{H}$. Identification and validation of Notch pathway activating compounds through a novel high-throughput screening method. Cancer. 2011; 117:1386-98. | Article | PubMed Abstract | PubMed Full Text

25. Chu D, Zheng J, Wang W, Zhao Q, Li Y, Li J, Xie H, Zhang H, Dong G, Xu $C, L i M, C h e n$ D and Ji G. Notch2 expression is decreased in colorectal cancer and related to tumor differentiation status. Ann Surg Oncol. 2009; 16:3259-66. | Article | PubMed

26. Fu YP, Edvardsen H, Kaushiva A, Arhancet JP, Howe TM, Kohaar I, Porter-Gill P, Shah A, Landmark-Hoyvik H, Fossa SD, Ambs S, Naume B, Borresen-Dale AL, Kristensen VN and Prokunina-Olsson L. NOTCH2 in breast cancer: association of SNP rs11249433 with gene expression in ER-positive breast tumors without TP53 mutations. Mol Cancer. 2010; 9:113. | Article | PubMed Abstract | PubMed Full Text

27. Zhu Y, Maric J, Nilsson M, Brannstrom M, Janson PO and Sundfeldt K. Formation and barrier function of tight junctions in human ovarian surface epithelium. Biol Reprod. 2004; 71:53-9. | Article | PubMed

\section{Citation:}

Galic V, Shawber CJ, Reeves C, Shah M, Murtomaki A, Wright J, Herzog T, Tong GX and Kitajewski J. NOTCH2 expression is decreased in epithelial ovarian cancer and is related to the tumor histological subtype. Pathol Discov. 2013; 1:4. http://dx.doi.org/10.7243/2052-7896-1-4 